\title{
World Community; and Remarks on our Own Behalf
}

\author{
Christopher Coenen
}

Published online: 17 April 2019

(C) Springer Nature B.V. 2019

We live in an era of growing tensions and are witnessing new surges of nationalism, religiously justified aggression and demagogy in many parts of the world, driven relentlessly forward by a global economic system that is increasingly destroying the planet's natural resources, including some that we need for life and for our livelihoods. Apparently, lessons learned during the decades of cruelty from World War I to the end of the Cold War have already been forgotten by many.

While always taking into account that science, in particular in the guise of technoscience, plays an important role in these destructive tendencies, we should also be concerned about the growing neglect of science and about the overt attacks on it from different sides. In this situation, we would be well-advised to reconsider the validity of a grand vision of the past: the hope that science will serve as a vehicle for global unification and the means by which to create a true world community. Of course, any such One World concept ought not to be based on the ideologies of Western supremacy, nor for that matter on those of any other kind of supremacy; it should be founded instead on ideas that promote, and

Electronic supplementary material The online version of this article (https://doi.org/10.1007/s11569-019-00338-3) contains supplementary material, which is available to authorized users.

C. Coenen $(\bowtie)$

Institute for Technology Assessment and Systems Analysis (ITAS), Karlsruhe Institute of Technology (KIT), Karlsruhe, Germany

e-mail: christopher.coenen@kit.edu indeed on practices that realise, a fair and respectful exchange on a global and local level.

If we take seriously the vision of science as a means not only of enabling humans to flourish but also of creating a world community, such ideas and practices also need to become more widespread in our small academic world. I am thus happy that we can publish a number of very apposite articles in the present issue of our journal NanoEthics: Studies of New and Emerging Technologies.

In his article in this issue, Koen Beumer describes and discusses the politically ambivalent role that nanotechnology has played and continues to play in India. He reveals how the mutual construction of nation-building and technology governance in a leading nation - whose leaders often have extremely high hopes of modern science and technology, not least as a result of their country's history during the period of European colonial imperialism - can reinforce certain views of the nation at the expense of others. With a view to understanding the challenges involved in the global governance of transnational movements and the impacts of science and technology, Beumer urges us to closely examine and learn from the divergent governance practices in place around the world, and not merely to focus on those countries in which modern science and technology have already been developing for a long time.

Ricardo Santana Cabello, Piedad Gañán Rojo, and Robin Zuluaga have conducted a thorough analysis of the history and application of the specific rules of nanotechnology enshrined in Regulation No. 1223/2009 of the European Parliament and of the European Council 
of 30 November 2009 on cosmetic products. In their insightful study, they conclude that the regulation, which was the result of a globally relevant governance process, has encountered technical obstacles, thus making it impossible to meet the objectives relating to nanotechnology that were proposed by the European Commission. In particular, they criticise shortcomings in the catalogue of nanomaterials and point out that the existing regulatory practices do not match the expectations of Members of the European Parliament.

The results of a remarkable project carried out in the United States of America on social and ethical aspects of nanoscience are reported and discussed in an article by Lee Ann Kahlor, Xiaoshan Li, and Jacy Jones. They describe the development and pilot testing of a training module for integrating such aspects into the lab. In their project, the authors explored how US nanoscientists perceive the social and ethical implications of nanotechnology, developed the module and subsequently tested it in a pilot study with nanotechnology undergraduate students on the one hand and nanoscientists on the other. They found that the students appreciated the training and wished that the ideas it contained would be incorporated into regular coursework and mentoring. The data from the scientists suggested that the training increased the perceived need for workplace routines to give consideration to social and ethical implications, and that it heightened the perceptions of risk associated with the scientists' own work.

In Europe, the continent that not only gave rise to so much suffering worldwide in modern times but which itself was the site of unspeakable horrors and utter devastation in the twentieth century, the spectres of the past have risen again and right-wing radicals and other enemies of humanity are back in most national parliaments. At such a sad juncture, Daniele Ruggiu's plea to exploit the full potential of the Council of Europe, and of the European Court of Human Rights (EctHR) in particular, is very important not only with respect to responsible research and innovation (RRI), which is the topic of his article. While much about the work of the Council of Europe can and indeed should be criticised, the author, quite rightly in our view, makes a strong argument about how important it and the ECtHR are. In his brilliant analysis, Ruggiu concludes by urging that the role of fundamental rights be strengthened in RRI by integrating in it a level of protection of human rights such as that provided for by the Council of Europe. In his opinion, this could help avoid what he terms 'irresponsible innovation' and improve the outcomes of public engagement with science technology, preventing relevant interests with a constitutional dimension from being sacrificed. On the other hand, he believes it could improve the outcomes of the trade-off made by states and the European Union, strengthening the position of rights as compared to other policy objectives in the field of innovation. Last but not least, Ruggiu's article, in which he discusses and refers to an impressive array of studies and empirical cases, demonstrates in passing how fascinating, inspiring and at times unsettling new and emerging technologies can be.

This editorial ends with a few remarks on our own behalf concerning the article categories that we feature in our journal, including some new ones (for a table with all categories, please see the table in the supplementary material), and touches upon some other aspects that might be of interest to you if you are considering submitting a paper to us.

While double-blind peer-reviewed papers covering original research constitute the large majority of all content featured in NanoEthics, the journal is open to consideration of any of the following categories of submission for publication: 'Original Research Paper', 'Discussion Note', 'Brief Communication', 'Introduction' (written by the editors of Special Sections in our journal), 'Response', 'Letter', 'Art-Science Interaction', 'Interview', 'Anecdote' and 'Book Review'. Furthermore, we have the categories 'Invited Contribution', 'Editorial', 'Erratum', and 'News', though no submissions are accepted for these. If you are interested in submitting a paper, please always let us know if it is intended as a contribution to a Special Section by choosing the article type 'Special Section' in the Editorial Manager system. However, please indicate also (in the notes concerning the manuscript in the EM system) the Special Section for which it is intended, the Special Section's guest editors with whom you are in contact, and the Article Category under which the paper falls.

The 'Original Research Paper' (formerly 'Original Paper') is the main category of articles published in our journal. An 'Original Research Paper' presents results of novel academic research. 'Original Research Papers' should have a minimum length of approx. 5000 words and a maximum length of approx. 15,000 words. We treat review papers as 'Original Research Papers', as long as they significantly contribute to progress in a field of study, for example by means of 
presenting a concise overview and a new interpretation of the state of the art in the given field of study. The peer-review process is double-blind.

The article category 'Discussion Note' (formerly 'Critical Discussion Notes') is a key element of NanoEthics, since our journal aims to be a forum for open discussion about all kinds of aspects of science and technology in society. 'Discussion Notes' are rather short (approx. 2000-5000 words), "essayistic" pieces, which can but do not need to be polemical. They are peer-reviewed with a view to their merits as thoughtprovoking essays that are relevant to ongoing or may stimulate new discussions, and with respect to such qualities as wit (esprit) as well as the usual quality criteria of academic publications (such as consistency, originality etc.). The peer-review is double blind.

A 'Brief Communication' is an article of not more than approx. 2500 words which reports on new, including preliminary, research results deemed by the EiC to be of utmost importance to our readership. The peer review of a 'Brief Communication' is double-blind or, if the EiC decides that its publication is very urgent, single-blind, but in both cases combined with an editorial review.

While other article categories (such as 'Original Research Paper' or 'Discussion Note') may also be used for submissions about or at the interfaces of art, literature, science, and technology, our journal also provides the article category 'Art-Science Interaction'. This category is primarily intended for artistic interventions and works at art-science-technology interfaces that do not correspond to any of the other article categories. The article category 'Art-Science Interaction' can, for example, be used for largely visual presentations of artistic work, or for fictional texts such as poems or short stories. Submissions to the 'Art-Science Interaction' category are reviewed by the EiC. Additional reviewers or advisers can be involved at the discretion of the EiC.

Anyone may propose to the editor-in-chief the publication of an interview on topics of interest to our readership. The length of an interview may be anything up to $\sim 15,000$ words, but the editor-in-chief may agree to even longer submissions. Interviews are reviewed by the editor-in-chief. Additional reviewers or advisers may be involved at the discretion of the editor-in-chief.

An 'Introduction' introduces a Special Section. Special Sections may be published in one issue or in up to three consecutive issues of our journal. If the Special Section is published in two or three issues, the
'Introduction' is always published in the first issue in which the Special Section is featured. In the running text, an 'Introduction' always provides at least brief information on all contributions to the Special Section. 'Introductions' can but do not need to provide a substantial overview on the state of the art and discussions on the topic of the Special Section and may provide further reflections on them. Accordingly, it can but does not have to include a list of references. Only the guest editors of the Special Section are invited to submit an 'Introduction' to it. 'Introductions' are reviewed by the editor-in-chief. Additional reviewers or advisers may be involved at the discretion of the editor-in-chief.

The article category 'Invited Contribution' mainly serves to publish articles whose authors are invited by the editor-in-chief to submit a text on a specific topic that the editor-in-chief deems crucial with respect to topics dealt with in the journal. Authors of 'Invited Contributions' will typically either work outside academia or be emeritus researchers and scholars. Unlike articles of other categories, the published articles do not need to be based on more recent manuscripts, as long as they are - for example due to their historical significance - relevant for current research and discussions. 'Invited Contributions' may also be translations of works previously published in languages other than English, as long as these works are landmark or important but internationally largely unknown studies. 'Invited Contributions' are reviewed by the editor-in-chief. Additional reviewers or advisers may be involved at the discretion of the editor-in-chief.

Letters to the editor are short contributions of not more than $\sim 2000$ words and can serve a variety of purposes. A 'Letter' can, for example, draw attention to a major problem in a field of science, technology, or scholarly research relevant to our journal's readership in a concise way, provide a short refutation of statements made in our journal (for longer refutations, see the article category 'Response'), or comment on crucial current developments relevant to research and innovation systems or to the role of science and technology in society (including, for example, political developments). A 'Letter' does not include a list of references but may mention publications in the running text.

'Response' is an article category of our journal that gives those criticised in it room for a substantial, detailed refutation. (For short refutations, the article category 'Letter' might be more appropriate. Since it is not usually possible to publish a 'Response' to a 'Response', 
the category 'Letter' may also be used to respond to a 'Response' to one's own article.) Anyone criticised in an article published in our journal is welcome to submit a 'Response' of up to approx. 5000 words. The response can point out inconsistencies in the published article, highlight further information, and may include a list of references. 'Responses' are reviewed by the editor-inchief. Additional reviewers or advisers may be involved at the discretion of the e. If individuals other than those criticised in a NanoEthics article want to submit a refutation, they are asked to use the article category 'Discussion Note'.

'Anecdotes' are short (up to approx. 2000 words) and often amusing accounts of an incident or event of an interesting nature. Our journal is open to publishing anecdotes if they can shed light on the history of, or the current state of affairs and open questions in, the fields of science and technology relevant to our readership, including the fields of scholarly research on science and technology present in the journal. The decision to publish an 'Anecdote' is taken by the editor-in-chief, who may seek advice from other members of the editorial team. 'Anecdotes' published in NanoEthics need to be based on the personal memory of the authors and shall not include explicit or implicit ad hominem at- tacks. Even if the personal memory is not entirely accurate, we deem such anecdotes relevant as a means for the authors, and perhaps others, to make sense of the fields they are working in or on.

The editor-in-chief may decide to publish news items in the journal. Since we do not aim to provide news on any regular basis, this category will only be used very rarely, for example for events co-organised by the journal. Submissions for the 'News' category are by invitation only.

Book reviews in NanoEthics usually have a length of approx. 2000-3000 words. The decisions to invite book reviewers and to accept book reviews for publication are taken by the editor-in-chief or by a NanoEthics editor in charge of the book review section. Everyone, including publishers and authors of the books in question, is welcome to propose a book review to the journal. Book reviews should however not be submitted without invitation, so please consult with the editors in case you want to propose one.

Publisher's Note Springer Nature remains neutral with regard to jurisdictional claims in published maps and institutional affiliations. 